\title{
Bhopal: the disaster continues
}

\author{
Dr Peter Wells \\ Cardiff Business School
}

The original Bhopal incident in December 1984 was, by any standards, an awful disaster for the community within which the Union Carbide factory was located. Even now, some twenty years later, the initial reaction is sheer anger at the loss of life and appalling injuries suffered by thousands upon thousands of innocent victims.

At the heart of the issue is the question of the purpose of corporations in society. The tradition from which Union Carbide arose is that of capitalist minimalism: the Stanford maxim of 'the purpose of business is business.' This is the Anglo-American business model that places shareholder sovereignty above all else. The rationality of profit maximization is apparently immune to dissent, and is so deeply ingrained in our collective psyche, that we are unable to question this logic. Yet it is equally valid to argue that business cannot relentlessly pursue profit at the expense of all other considerations, indeed it is irrational so to do. More fundamentally, business is a social institution and, if it fails to serve social needs then it loses legitimacy.

The tragedy of Bhopal is that of a society without the control mechanisms, without the social, political, legal, economic and cultural mechanisms to control the excesses of capitalist minimalism. In this way Bhopal has become emblematic, it encapsulates and magnifies so many issues that were not only relevant then, but sadly are equally or more relevant today. Bhopal resonates with our sense of all that can go wrong, and then with the utter failure of those who suffer to find adequate redress. In this respect the devastation loosed upon the people of Bhopal by the Union Carbide factory, while it itself a terrifying incident, should not simple be seen in isolation as the unique outcome from a specific set of circumstances. Just as the problems at Enron have forced US financial regulators and institutions to rethink their approach to corporate governance and accounting, or indeed just as the attack on the World Trade Center met with the all-out 'war on terror' and Homeland Security, it is vital that Bhopal be seen in its wider context. Bhopal is therefore symbolic of:

- The plundering of local communities and their resources by large multinational companies regardless of the cost to those communities;

- The duplicity of standards that apply in some places but not in others;

- The global fluidity of capital, compared with the huge barriers erected against the movement of people;

- The abject failure of local, city, regional and national governments in developing countries to take on powerful multinational companies;

- The low value of a human life in developing countries compared with developed countries;

- The unforgivable lethargy of the system of redress for the victims or corporate carnage;

- The lack of local accountability or control;

- The lack of local knowledge or understanding about technologies, chemicals, processes, and many aspects of manufacturing that results in communities ignorant of what actually goes on in the factories around which they live;

- The way in which the poor and powerless of any country are always the victims. 
In other words, Bhopal is symbolic of a sort of cultural collision that provides the raw ingredients for similar human and ecosystem disasters around the world.

China has sought to manage this collision with a 'one country, two systems' approach that allows the parallel co-existence of the state controlled industries and the inward investments of Western capitalist enterprises: it remains to be seen whether such institutional schizophrenia is viable. The need for investment for many countries is undeniable, but so too is the need for these countries to be protected from the negative consequences of such investment. Bhopal crystalised these problems into one devastating night, and hence made them visible. In the contemporary era perhaps the negative impacts are more diffuse, spread over space and time and so we don't see them. This does not mean that disasters no longer happen.

We are all still in thrall to capital. Individuals and companies generate wealth out of the societies within which they are hosted, but can abstract that wealth for themselves. We have acquiesced to a world in which the movement of money acts as a form of trans-boundary pollutant, rending apart cultures in the search for evergreater financial returns. The model of business in mainland Europe, while not perfect, at least recognizes that there is a social contract between business and the communities within which it operates. Strangely, many of these seemingly allpowerful companies vilified by the anti-globalisation protesters are themselves horribly weak and ephemeral...and it is this vulnerability that in part drives the globalisation process.

It is of course true that the world has changed since 1984. People in developing countries are probably better informed for example, while CNN can bring live footage of an unfolding catastrophe to the homes of millions in North America and Europe. Yet Bhopal has to be more than a fascinating case study in the epidemiology of poisoning by gas clouds. If we are to give the victims of Bhopal true justice it lies not simply in retribution or even financial compensation - although that is a right and proper place to start. Justice lies in creating the international legal controls and systems that treat the companies that commit these acts with the same vigour and resolve that is currently reserved for the followers of Bin Laden.

It is hard not to draw comparisons with the more recent disaster of the World Trade Center in New York. Both incidents resulted in enormous human suffering, in both cases people grieved for loved ones, yearned for explanations, and wanted the guilty to be called to account. In the Bhopal case, the initial incident has been followed by years of confusion and chaos, with a long struggle for retribution and recompense for people who were in any case among the poorest in the world. In New York, the initial incident triggered the huge, and obscene, expenditures on the invasion of Iraq and the paranoia of the Homeland Security regime. 